\title{
Reconsidering the Role of Money for Output, Prices and Interest Rates*
}

\author{
Giovanni Favara ${ }^{\dagger}$ and Paolo Giordani ${ }^{\ddagger}$ \\ SSE/EFI Working Paper Series in Economics andFinance No.514. \\ First Draft: September 2001 \\ This Version: November 2002
}

\begin{abstract}
New Keynesian models of monetary policy assign no role to monetary aggregates, in the sense that the level of output, prices, and interest rates can be determined without knowledge of the quantity of money. We evaluate the empirical validity of this prediction by studying the effects of shocks to monetary aggregates using an identified VAR. Shocks to monetary aggregates are isolated by means of identifying restrictions suggested by this class of models. Contrary to the theoretical predictions, shocks to broad monetary aggregates have substantial and persistent effects on output and prices.
\end{abstract}

Keywords: New Keynesian models, LM shocks, VAR, Block-exogeneity.

JEL:E 31, E 52, E 58.

\section{Introduction}

In recent years it has become standard practice to discuss monetary policy without any reference to monetary aggregates. The main factor underlying this phenomenon is the observation that central banks have de-emphasized the role of money for gauging economic and financial conditions.

Consistently with this practice, New Keynesian models of monetary policy have emerged as the most common framework for discussing the consequences for inflation and output of adopting alternative interest rate rules. The benchmark setup involves the assumption of price stickiness and is defined in terms of an IS equation, which relates output to the real interest rate, an AS/Phillips

${ }^{*}$ We thank Eric Leeper, Giorgio Primiceri, Chris Sims, Lars Svensson, Paul Söderlind, Andrea Tambalotti, Anders Vredin, Mike Woodford, and seminar participants at the IIES and the Sverige Riksbank in Stockholm.

†IIES, Stockholm University and Princeton University: e-mail favarag@iies.su.se and gfavara@princeton.edu

${ }^{\ddagger}$ Stockholm School of Economics: www.hhs.se $\backslash$ personal $\backslash$ Giordani. 
curve, which expresses the rate of inflation as a function of the level of economic activity, and an interest rate rule, which summarizes the way monetary policy is implemented. An important feature of this class of models is that money plays no role. In fact, under the assumption that the monetary authority sets the interest rate, there is no need to specify a traditional LM equation. The model's mechanics imply that the central bank supplies any quantity of money demanded by the market at a given interest rate. Shifts in money demand are perfectly accommodated and have no effect on the remaining set of variables. The interest rate rule and the $I S$ - $A S$ relations form a complete system of equations for the determination of interest rates, inflation and output. ${ }^{1}$

The quantitative implications of excluding money from a standard monetary model with optimizing agents have been recently investigated by Woodford (2002) and McCallum (2001). Both consider standard setups where individuals value money because it facilitates transactions for purchasing consumption goods. Under reasonable parameter values (calibrated on U.S. data), they show that little is lost for the equilibrium determination of output and inflation by assuming away any role for money. Woodford, for instance, warrants that "...with an interest rate rule...the equilibrium paths of inflation and output can be understood without reference to the implied path of the money supply or the determinants of money demand." (Woodford, 2002, ch. 4)

These sharp conclusions, however, stand in contrast with the conflicting results of the empirical literature. The available evidence can be grouped in two categories. The first examines the role of money using $F$-tests on simple reduced form equations for output and inflation. The second adopts a more structural approach, estimating coefficients related to money in models of monetary policy with a backward looking or microfounded forward looking structure.

Notable examples in the first category are Friedman and Kuttner (1992, 1996) and Estrella and Mishkin (1997). They provide evidence that the predictive role of money for output and inflation has evaporated in the USA after the 80 's, due to the erratic behavior of money's velocity. These well-known results contrast with those of Stock and Watson (1989) and Feldstein and Stock (1993), who find that money contributes to predicting part of the subsequent fluctuations in output not already predictable from past values of output, prices and interest rates.

An equally opaque picture emerges from the second group of works. For example, Rudebusch and Svensson (2001), fit a small $A S$ - $A D$ model to U.S. data and find that nominal money is insignificant in their structural equations. ${ }^{2}$ Conversely, Nelson (2000), despite using the same model as Rudebusch and

\footnotetext{
${ }^{1}$ This feature of New Keynesian models is of course also inherent in the older Keynesian theory as formulated in the IS-LM model. It is therefore not surprising that it characterizes both backward looking and forward looking models of monetary policy. For models with a backward looking structure see, among others, Svensson (1997), Ball (1997), Taylor (1999), Rudebusch and Svensson (2002). For forward looking models see Rotemberg and Woodford (1997), McCallum and Nelson (1999), Clarida, Gali and Gertler (1999), Woodford (2002).

${ }^{2}$ For similar reasons, Gerlach and Smets (1996) propose an empirical model of the monetary transmission mechanism in the G7 countries which includes output, inflation and a short interest rate, but no monetary aggregate.
} 
Svensson, concludes that money is a significant determinant of aggregate demand, both in the U.S. and in the U.K., even after controlling for the short term real interest rate. ${ }^{3}$ Other important contributions are given by Ireland (2001) and Leeper and Zha (2000). In an estimated forward looking equilibrium model for the U.S. economy, Ireland finds that real money balances fail to enter either the $I S$ or the Phillips curve. Leeper and Zha (2000), instead, using a VAR analysis, conclude that the exclusion of money from this class of models is not empirically innocuous as the interpretation of the historical policy behavior changes substantially once money is reintroduced in the analysis.

This paper aims to provide new empirical evidence on the role of money for output, prices and interest rates. We use an identified vector autoregression (VAR) to examine the role played by shocks to the LM equation in shaping the dynamic behavior of output, inflation and interest rates. A distinctive feature of our VAR analysis is that both the variables included in the system and the identifying restrictions used to isolate shocks to the LM equation are suggested by the class of models that assign a marginal role to monetary aggregates. As mentioned above, a common prediction of all these models is that shocks to the LM curve have no effect on output, prices and interest rates. Our results, using U.S. data for the period 1966-2001, suggest that this prediction is not correct, since LM disturbances significantly affect the dynamic behavior of output and, to a larger extent, of inflation.

The paper is organized as follows. Section 2 defines a broad class of models which give a marginal role to money. It argues that within these models LM shocks can be identified by a triangular orthogonalization, and that following an LM shock, responses of all variables other than money ought to be flat. Section 3 tests this prediction on US data. Section 4 conducts several robustness checks, while Section 5 presents evidence based on block-exogeneity tests. Section 6 offers concluding remarks.

\section{The effects of LM shocks: Theoretical predic- tions}

This section presents a small structural model extensively used to study monetary policy, as in Clarida et al. (1999) and Woodford (2002). The model has a forward looking structure and consists of three key equations: an aggregate supply (AS curve), an aggregate demand (IS curve) and a policy rule:

$$
\begin{gathered}
\pi_{t}=\beta E_{t} \pi_{t+1}+\kappa x_{t}+\epsilon_{t}^{s}, \\
x_{t}=E_{t} x_{t+1}-\sigma\left(i_{t}-E_{t} \pi_{t+1}\right)+\epsilon_{t}^{d} \\
i_{t}=f_{\pi} \pi_{t}+f_{x} x_{t}+\epsilon_{t}^{p},
\end{gathered}
$$

\footnotetext{
${ }^{3}$ Meltzer (1999) is another example where real money affects aggregate U.S. consumption. He argues that his finding supports the validity of a real balance effect for aggregate demand. Evidence against a real balance effect in U.S. data can be found, instead, in Reifshneider, et al. (1999).
} 
where $x_{t} \equiv y_{t}-y_{t}^{n}$, is the output gap (defined as the deviation of actual output $y_{t}$ from potential, $\left.y_{t}^{n}\right), \pi_{t}$ is the rate of inflation between period $t-1$ and $t$, and $i_{t}$ is the short term nominal interest rate and the central bank's instrument. $E_{t} \pi_{t+1}$ and $E_{t} x_{t+1}$ denote the expectations of inflation and output gap at $t+1$ conditional upon information available at time $t ; \beta \kappa, \sigma f_{\pi}$ and $f_{x}$ are structural parameters and $\epsilon_{t}^{s}, \epsilon_{t}^{d}, \epsilon_{t}^{p}$ are exogenous disturbances interpretable as unobservable additional determinants of inflation, output gap and interest rate.

Equations (1), the AS curve, and (2), the IS curve, are obtained from microeconomic foundations: the AS curve derives from the optimal pricing decision by monopolistically competitive firms; the IS curve is obtained from the Euler equation for consumption of a representative utility-maximizer household. Conversely, the policy rule is not derived from first principles and is in fact postulated ad hoc, in the spirit of a "Taylor rule", though the optimal reaction function of a central bank that has a quadratic loss function in inflation and output gap may take a similar form (see e.g. Svensson, 1997, or Svensson, 2002).

One of the starking features of this simple model is the lack of reference to monetary aggregates. Subsumed in the derivation of equations (1) and (2) is the assumption that the economy operates in a "cashless limit" environment, where monetary frictions are negligible or the equilibrium money balances are sufficiently small to have material effect on output and inflation (see Woodford, 2002). Within this framework the level of inflation and output is independent of the amount of real money balances in the economy and the system of equations (1)-(3) is sufficient to determine the time path of the endogenous variables, $\left\{\pi_{t}, x_{t}, y_{t}, i_{t}\right\}$ given the evolution of the exogenous processes $\left\{y_{t}^{n}, \epsilon_{t}^{s}, \epsilon_{t}^{d}, \epsilon_{t}^{p}\right\}$.

The same result arises in the more familiar environment where money supplies liquidity services and the household utility function is assumed separable in consumption and money holdings. In this case, a log-linear approximation to the first order conditions for the representative household's optimal demand for money balances yields a conventional LM equation of the form

$$
m_{t}=h y_{t}-\eta i_{t}+\epsilon_{t}^{l},
$$

where $m_{t}$ is the level of real money balances, $h$ and $\eta$ are positive parameters and $\epsilon_{t}^{l}$ is a disturbance which, in principle, can be correlated with disturbances affecting the IS equation. ${ }^{4}$ Money is redundant within this class of model: the level of real money balances is demand determined given the interest rate and the level of output, which are endogenously determined by equations (1)(3). Hence, equation (4) serves the sole purpose of determining the quantity of money the central bank needs to supply to clear the money market, but money itself has no role for the equilibrium determination of output and prices. Since the monetary authority fixes the interest rate and accommodates shocks to the LM equation through passive expansions of the money supply, the equilibrium values of output, inflation and interest rate are not altered by disturbances to

\footnotetext{
${ }^{4}$ In the model used by Woodford $(2002, \mathrm{ch} .2)$, for example, the residual term $\epsilon_{t}^{l}$ is a linear combination of preference shocks and government consumption shocks which in his model are shocks affecting the IS equation.
} 
the LM curve. It is precisely for these reasons that standard New Keynesian models of monetary policy make no reference to monetary aggregates and attach no importance to the determinants of money demand or the evolution of money supply. ${ }^{5}$

In the remaining part of this section we argue that this theoretical prediction can be tested using a vector autoregression (VAR) and in the following sections we evaluate its empirical relevance. We will show that these theoretical prediction is not empirically supported because exogenous shocks to the LM equation affect in a remarkable way the dynamics of output, prices and interest rate.

\subsection{The state-space and VAR representation}

Assuming that the vector of predetermined variables $\epsilon_{t}^{\prime}=\left\{y_{t}^{n}, \epsilon_{t}^{s}, \epsilon_{t}^{d}, \epsilon_{t}^{p}, \varepsilon_{t}^{l}\right\}$ follows a $\operatorname{VAR}(1)$ stochastic process with orthogonal innovations $v_{t}^{\prime}=\left\{v_{t}^{d}, v_{t}^{n}\right.$, $\left.v_{t}^{s}, v_{t}^{p}, v_{t}^{l}\right\}$, the system of equations (1)-(4) can be conveniently re-written in the following state-space form:

$$
\mathbf{A}\left[\begin{array}{c}
\epsilon_{t+1} \\
E_{t} X_{t+1}
\end{array}\right]=\mathbf{B}\left[\begin{array}{c}
\epsilon_{t} \\
X_{t}
\end{array}\right]+\mathbf{C} i_{t}+\left[\begin{array}{c}
v_{t+1} \\
0_{n_{X} \times 1}
\end{array}\right],
$$

with

$$
\epsilon_{t}=\left[\begin{array}{c}
y_{t}^{n} \\
\epsilon_{t}^{s} \\
\epsilon_{t}^{d} \\
\epsilon_{t}^{p} \\
\epsilon_{t}^{l}
\end{array}\right] \quad X_{t}=\left[\begin{array}{c}
y_{t} \\
\pi_{t} \\
m_{t}
\end{array}\right] \quad v_{t}=\left[\begin{array}{c}
v_{t}^{n} \\
v_{t}^{s} \\
v_{t}^{d} \\
v_{t}^{p} \\
v_{t}^{l}
\end{array}\right],
$$

where $\mathbf{A}, \mathbf{B}$ and $\mathbf{C}$ are matrices of coefficients; $\epsilon_{t}$ is a $\left(n_{\epsilon}, 1\right)$ vector of predetermined variables, with $\epsilon_{0}$ given; $X_{t}$ is a $\left(n_{X}, 1\right)$ vector of forward looking variables; $v_{t}$ is a $\left(n_{\epsilon}, 1\right)$ vector of orthogonal innovations, with a diagonal covariance matrix , and $i_{t}$ - the policy instrument - is a linear function of predetermined and forward looking variables

$$
i_{t}=-\underset{1 \times\left(n_{\epsilon}+n_{X}\right)}{\mathbf{F}}\left[\begin{array}{c}
\epsilon_{t} \\
X_{t}
\end{array}\right] .
$$

\footnotetext{
${ }^{5}$ This general result holds also in a model with cash in advance constraints but is no longer valid if the utility function is non-separable in money and consumption or if the liquidity services of money are modelled through the household budget constraint, as in McCallum (2001). In these last two cases the level of real money balances matters in both the IS and AS relation. Woodford (2002) and McCallum (2001) argue, however, that even within these more realistic models the importance of real money balances is negligible when the parameters are calibrated on U.S. data, and thus the baseline model without money (equations (1)-(3)) still remains a good benchmark to study monetary policy.

In the remaining sections we will restrict our attention to the case where the underlying household utility is additively separable between consumption and real balances. This special class of utility functions enables us to isolate LM shocks and evaluate their effects on output, prices and interest rates. The general purpose of our exercise is, in fact, to show that neglecting a role for money in the standard three equation model of monetary policy is not without consequences from an empirical point of view; a claim that goes beyond the general preference specification adopted to evaluate consumption and real money balances.
} 
Without loss of generality we have placed money $\left(m_{t}\right)$ last in vector $X_{t}$ and the orthogonal innovation to the LM equation $\left(v_{t}^{l}\right)$ last in vector $v_{t}$. The consequence of this ordering is that the $\mathbf{A}$ and $\mathbf{B}$ matrices have the following form (with $\left.n=n_{X}+n_{\epsilon}\right)$

$$
\left[\begin{array}{c|c}
\mathbf{A}_{(n-1) \times(n-1)} & 0 \\
& \vdots \\
\hline 0_{1 \times(n-1)} & 0_{1 \times 1}
\end{array}\right]
$$$$
\left[\begin{array}{c|c}
\mathbf{B}_{(n-1) \times(n-1)} & 0 \\
& \vdots \\
\hline b_{1 \times(n-1)} & b_{1 \times 1}
\end{array}\right],
$$

where the fact that the first $n-1$ entries of the last column of $\mathbf{A}$ and $\mathbf{B}$ are zero corresponds to the assumption that money does not enter any of the structural equations (1)-(2) nor the interest rate rule (3). Moreover, the non-zero entries in the last row of $\mathbf{B}$ allow for the possibility that the disturbance to the LM equation $\left(\epsilon_{t}^{l}\right)$ is a linear combination of all disturbances affecting the IS and AS equations. ${ }^{6}$

Using standard methods (see, e.g., Söderlind, 1999), the solution to (5) can be written as:

$$
\begin{aligned}
\epsilon_{t+1} & =\underset{\left(n_{\epsilon} \times n_{\epsilon}\right)}{\boldsymbol{\Lambda}} \epsilon_{t}+v_{t+1} \\
Y_{t} & =\left[\begin{array}{c}
i_{t} \\
X_{t}
\end{array}\right]=\underset{\left(n_{X+1}\right) \times n_{\epsilon}}{\boldsymbol{\Gamma}} \epsilon_{t},
\end{aligned}
$$

so that the stacked vector $\left(Z_{t}\right)$ of potential output, control variables and endogenous variables can be expressed as a linear function of predetermined variables:

$$
\underset{\left(n_{Z} \times 1\right)}{Z_{t}}=\left[\begin{array}{c}
y_{t}^{n} \\
Y_{t}
\end{array}\right]=\left[\begin{array}{c}
\boldsymbol{\Lambda}_{1} \\
\boldsymbol{\Gamma}
\end{array}\right] \epsilon_{t}=\underset{\left(n_{Z} \times n_{\epsilon}\right)}{\mathbf{P}} \epsilon_{t},
$$

where $\boldsymbol{\Lambda}_{1}$ is the first row of $\boldsymbol{\Lambda}$, and $n_{Z}=n_{\epsilon}$. Since the matrices $\boldsymbol{\Lambda}$ and $\boldsymbol{\Gamma}$ depend on the matrices of the structural parameters (A, B and $\mathbf{C}), \boldsymbol{\Lambda}$ and $\mathbf{P}$ take a well-defined form, in which the last column is made of zeros with the exception of the last entry:

$$
\boldsymbol{\Lambda}=\left[\begin{array}{c|c}
\Lambda_{\left(n_{\epsilon}-1\right) \times\left(n_{\epsilon}-1\right)} & 0 \\
& \vdots \\
\hline \lambda_{1 \times\left(n_{\epsilon}-1\right)} & \lambda_{1 \times 1}
\end{array}\right], \mathbf{P}=\left[\begin{array}{c|c}
P_{\left(n_{Z-1} \times n_{\epsilon-1}\right)} & 0 \\
& \vdots \\
\hline p_{1 \times\left(n_{\epsilon}-1\right)} & p_{1 \times 1}
\end{array}\right],
$$

\subsubsection{Implications}

We now discuss the implications that the form of the $\boldsymbol{\Lambda}$ and $\boldsymbol{\Gamma}$ matrices have for evaluating the consequences of shocks to the LM equation. First, notice that the dynamics of the variables of interest, i.e. the vector $Z_{t}$, can be examined

\footnotetext{
${ }^{6}$ The zeros in the last row of the $\mathbf{A}$ matrix arise, instead, because the LM equation (4) is static. A more elaborated version of this equation involving leads and lags of money holdings (possibly derived from portfolio adjustment costs) will not invalidate the results that follow. A detailed state space representation of the system of equations (1)-(4) is given in the Appendix.
} 
through a VAR model. Equation (10) can be used to express (8) in terms of $Z_{t}$ only

$$
Z_{t}=\mathbf{P} \boldsymbol{\Lambda} \mathbf{P}^{-1} Z_{t-1}+\mathbf{P} v_{t}
$$

which is a standard reduced form VAR(1) representation:

$$
Z_{t}=\mathbf{T} Z_{t-1}+u_{t}
$$

where

$$
\mathbf{T}=\mathbf{P} \boldsymbol{\Lambda} \mathbf{P}^{-1}
$$

is the matrix of the reduced form coefficients and

$$
u_{t}=\mathbf{P} v_{t}
$$

are the reduced form residuals with variance-covariance matrix given by:

$$
\boldsymbol{\Omega}=E\left(u_{t} u_{t}^{\prime}\right)=\mathbf{P} E\left(v_{t} v_{t}^{\prime}\right) \mathbf{P}^{\prime}=\mathbf{P P}^{\prime} .
$$

Second, recalling that money is ordered last in the vector $Z_{t}$, equations (11) and (14) imply that the idiosyncratic innovation to the LM equation $\left(v_{t}^{l}\right)$ can be easily identified through a Cholesky decomposition of the variance-covariance matrix $\Omega$.

Third, the restrictions on $\boldsymbol{\Lambda}$ and $\mathbf{P}$ imply that the first $n_{Z}-1$ elements of the last column of $\mathbf{T}=\mathbf{P} \boldsymbol{\Lambda} \mathbf{P}^{-1}$ are zero. It follows that the impulse response functions

$$
Z_{t+s}-E_{t} Z_{t+s}=\sum_{j=0}^{s-1} \mathbf{T}^{j} \mathbf{P} v_{t+s-j}
$$

of variables in $Z_{t}$ other than money, to LM shocks (the last element of the vector $v_{t}$ ) will be flat at all horizons. ${ }^{7}$

In summary, the discussion of this section suggests that the predictions concerning the effects of shocks to the LM relation in a standard New Keynesian model can be evaluated using an empirical VAR model, with output, output gap (or potential output), inflation, interest rate and money as included variables. The prediction that money is irrelevant for output and inflation determination can then be tested in two steps. First, LM shocks are identified through a Cholesky decomposition, ordering money last in the VAR. Second, following a shock to the LM equation the impulse response functions are compared with their predicted values, which are zero at all horizons for all variables other than money.

We close this subsection with a final remark concerning the generality of the procedure just discussed. It is worth emphasizing that this procedure is not only valid for the model sketched in equation (1)-(2), rather it is applicable to a larger class of models. In fact, models with richer dynamics or with no forward looking structure -such as those used in Svensson (1997), Ball (1997), Taylor

\footnotetext{
${ }^{7}$ Recall that because $m_{t}$ is the last variable in the VAR, the last column of the matrices $\mathbf{T}^{j} \mathbf{P}$ contains the impulse vector to an LM shock.
} 
(1999) or Rudebusch and Svensson (2002) - can still be cast in the state space representation given by (5) and the same implications discussed above apply, insofar as, in any of these models, money plays a redundant role. The crucial requirement is that money does not appear in any structural equation, including the central bank reaction function.

\subsubsection{Discussions}

The general procedure just outlined is based on the crucial assumption that $n_{Z}=n_{\epsilon}$. This assumption guarantees that $\mathbf{P}$ is invertible and, given equation (14), there exist a mapping between reduced and structural form residuals. In words, it amounts to stating that the number of disturbances in the model (possibly including measurement errors) is the same as the number of endogenous variables. It thus requires that the model under consideration is correctly specified. Whether this assumption is crucial for evaluating the importance of money is a question that deserves further discussion.

Case 1: Consider first the case where $n_{Z}>n_{\epsilon}$. One such case (which is also the most relevant one for our purpose) may arise if the disturbance to the LM equation is a linear combination of disturbances to the other equations in the system. In this situation the corresponding structural innovation $v_{t}^{l}$ is zero, meaning that there is not an idiosyncratic shock to the LM equation and hence the probability distribution of the vector of endogenous variables (including money) is degenerate. In fact, as can be seen from equation (14), the variance covariance matrix of the reduced form VAR $(\Omega)$ will be singular if the variance covariance matrix of the structural innovations is singular. In practise, however, these singularities are hard to find and there is no sign of such problem in the VARs we estimate. ${ }^{8}$ We thus believe that such case is negligible from an empirical point of view.

Case 2: The case where $n_{Z}<n_{\epsilon}$ is more problematic and would be a symptom of omitted variables. This has important implications for our analysis, for the following reason. When money is ordered last in a Cholesky decomposition, a necessary and sufficient condition for the impulse responses to a LM shock to be zero is that money does not Granger-cause the set of remaining variables in the VAR system (see Lutkepohl, 1993, Proposition 2.2). Thus, testing money redundancy is equivalent to testing that other variables in the system are block-exogenous with respect to money, i.e. money does not help to improve the forecast of any other variable in $Z_{t}$ at any horizon (see the discussion in Section 5). However, if some omitted variable had forecasting power for both money and some other variable in the VAR, then its omission might lead to the conclusion that money is not redundant. In this case, money could act as a proxy for the omitted variable. For this reason, in Section 4.3 we investigate the sensitivity of our results to the inclusion of additional variables suggested by extensions of the baseline model given by (1)-(4).

\footnotetext{
${ }^{8}$ See Schorfheide (2000) for a related point.
} 


\section{The effects of LM shocks: evidence from a recursive VAR}

To test the prediction of flat responses to LM shocks, we estimate a VAR on quarterly U.S. data for the period 1966:1-2001:3. As suggested by the New Keynesian framework, our benchmark VAR includes output, output gap, a price index, a short interest rate and money. ${ }^{9}$ In contrast with the empirical literature on monetary policy, we do not include a commodity price index to avoid "the price puzzle". ${ }^{10}$ For reasons explained in Giordani (2000), a commodity price index is not needed if the VAR includes a good measure of the output gap, as explicitly suggested by theory.

In our VAR, the federal funds rate is the policy instrument, and based on the results of the previous section, shocks to the LM equation are identified by applying a Cholesky decomposition to the reduced form covariance matrix, with money ordered last. This identification imposes that LM shocks have no effect on any variable (other than money) within the period. The remaining shocks are left unidentified and the ordering of the other variables is irrelevant for evaluating the effects of a shock to the LM equation. The VAR is estimated with four lags.

The estimated impulse response functions of all variables to an LM shock are plotted in Figure 1. Contrary to the prediction of the theory, the responses of all variables are significantly different from zero for several quarters. Output and the output gap display a hump-shaped response, reaching a peak after 4 quarters. The price index reacts strongly and persistently: after the first period the response remains highly significant for a four-year horizon. At that horizon M2 and CPI have both increased by approximately the same amount.

A final notable feature of Figure 1 is that the federal funds rate's response is positive, significant and prolonged. This finding does not have a straightforward interpretation. It could reflect the endogenous response of policy - via a Taylortype policy rule - to increases in inflation and output following a shock to monetary aggregates. Alternatively, it may represent the direct policy response to monetary aggregates innovations, or a combination of both effects. We briefly consider this problem in Section 4.4.

We next examine the relative contributions of LM shocks to the variance of the $k$-step-ahead forecast errors in prices, output, output gap and federal funds rate. The results are reported in Table 1. Surprisingly, LM shocks are a large source of disturbance for the price index, accounting for $23 \%$ of its forecast variance after 8 quarters and for $43 \%$ after 16 quarters. The contribution of LM shocks to the variance decomposition of the output gap and output is smaller

\footnotetext{
${ }^{9}$ The VAR includes real GDP (logged), a measure of capacity utilization in the manufacturing sector produced by the Federal Reserve Board, CPI (logged), the federal funds rate, and M2 (logged). All data are from the database FRED, aggregated from monthly data (except capacity utilization) and s.a. (except the federal funds rate). All series used in this paper are available at: www.hhs.se $\backslash$ personal $\backslash$ Giordani.

${ }^{10} \mathrm{~A}$ commodity price index is included in one of the robustness checks discussed in Section 4.3 .
} 
but not negligible; it is around $20 \%$ and $13 \%$ respectively after 16 quarters, and somewhat larger than the contribution of monetary policy shocks. ${ }^{11}$

\section{Robustness of the results}

To check the robustness of our results, we have conducted several experiments. Robustness checks address sub-sample stability, alternative measures of prices and money, inclusion of additional variables, and identification. Figures 6a-6d report the impulse response functions to LM shocks for several specifications of the VAR, which we now discuss.

\subsection{Sub-sample stability}

Our sample period includes two oil shocks during the 70's and arguably at least one change in the policy function of the Fed, conventionally dated around 1979 (see for example Bernanke and Mihov, 1998). In an attempt to control for these events we have re-estimated the benchmark VAR over the period 1980:12001:3 as, for example, in Rotemberg and Woodford (1997). The results are shown in the first column of Figure 6a. Although the impulse responses in the shorter sample are less precisely estimated, the qualitative results do not change. A closer look at impulse response functions and variance decomposition (not shown) reveals that the role of LM shocks is substantially reduced. The standard deviation of LM shocks is also smaller in this sub-sample. These last results seem to support the conventional wisdom that the predictive role of monetary aggregates has decreased in the last two decades. While suggestive, this interpretation fails to explain why, at all horizon, each variable in the VAR (and not just money) has smaller variance and is less important in the variance decomposition of all variables other than itself.

Small sample bias may also be partially responsible for the smaller responses in the post-1980 sample. In our benchmark VAR all variables are persistent, with CPI and M2 close to be integrated of order two. Thus the bias may be severe on the reduced sample. In fact, if the VAR is estimated using annual inflation and real money, the results are closer to those for the entire sample though the responses remain smaller (see column 2).

The sample period under consideration includes the interval 1979-1982, in which the Fed officially targeted non-borrowed reserves. Figure 2 plots the estimated LM shocks for the full sample to check if there are anomalies in the estimated residuals. The plot reveals that, with the exception of an outlier in 1983:1, the residuals do not exhibit erratic behavior. The results are unaffected if we dummy out this outlier, or if the benchmark VAR is estimated over the

\footnotetext{
${ }^{11}$ Following a common practice in the VAR literature on monetary policy, we identify the monetary policy shock as the residual in the federal funds rate's equation. In the Cholesky decomposition, the federal funds rate is ordered after output gap, output and the price index and before money.
} 
sample 1983:4-2001:3, as shown in the third column of Figure 6a: the effects on output gap, prices, and interest rate are unaltered.

We have also considered the effects of the break in the money demand equation that some researchers have documented for the early 90 s. It turns out that for both M2 and M3 this break is less clear than for M0 and M1. The CUSUM test is passed at $5 \%$ only if a post-1990 intercept dummy (which takes the value of zero up to 1989:4 and unity thereafter) is included in the equation. Yet, augmenting the VAR with this dummy (in all equations) does not produce sizable changes as shown in the last column of Figure 6a.

\subsection{Alternative VAR specifications}

As a further check, we have investigated how sensitive our results are to different VAR specifications. The results are displayed in Figure 6b. In the first column, we used GDP deflator rather than CPI. In column 2 we replaced M2 with M3 and, in another attempt (not shown), switched the order of interest rate and M2 in the Cholesky decomposition - though this is not justified by the model. In all cases, the responses of all variables to an LM shock are essentially unaltered. The last two columns of Figure $6 \mathrm{~b}$ assess the effects of LM shocks using M0 or M1. For both measures of money, the responses of prices and of the federal funds rate are qualitatively similar to those obtained when broader aggregates are used, but smaller and less precisely estimated. The responses of output gap and output, on the other hand, are never significantly positive, suggesting that the choice of a broad monetary aggregate is crucial for the results of Section $3 .^{12}$

\subsection{Enlarged VARs}

In sub-section 2.1.2, we anticipated that spurious results can be obtained if relevant variables are omitted from the VAR. Motivated by this concern, we have added several additional determinants of output and inflation. Some of these variables are potentially useful predictors of inflation and output; others are suggested by extensions of the standard New Keynesian framework of Section 2. In all cases, M2 is ordered last to maximize the severity of the robustness checks. The results are reported in Figure 6c and 6d.

Financial Variables The most immediate financial variable to consider is the long-term interest rate (the yield on 10 year government bonds). Nelson (2000) has suggested that the direct effect of real money on aggregate demand may be a proxy for an effect operating via a long interest rate. Our orthogonalization enables us to check this prediction, expecting LM shocks to have no effect on output and prices once the long-term interest rate is controlled for. As shown in

\footnotetext{
${ }^{12}$ The response of real GDP to M1 is anomalous, declining significantly for 15 periods after an LM shock. This result is driven by the last few years of the sample, and may be due to the well-known instability of M1. The response of GDP becomes insignificant if the VAR is estimated up to 1995 .
} 
the first column of Figure 6c, the impulse responses do not support this prediction and our benchmark results remain virtually unaffected. Similar conclusions arise if a term spread is included in the VAR: neither the short end of the government bond yield curve (6-month minus 3 -month) nor the spread involving a long rate (10-year minus 3-month) produce any changes worth reporting.

Several papers in the literature have shown that default spreads are good predictors of output and inflation (see the extensive survey in Stock and Watson, 2001). Among others, Friedman and Kuttner (1992) have found that when the spread between commercial paper and U.S. Treasury bill is used, the predictive content of monetary aggregates for output and prices is wiped out. In the second column of Figure 6c we report our set of responses after controlling for the paper-bill spread at 3-month maturity. Once again, there are no appreciable differences in the results.

The overall pattern of impulse responses remains unaffected if we include an index of stock prices, as shown in the third column. In this last case the only change worth noticing is the reduced response of prices to LM shocks. However, if an alternative measure of stock market conditions is considered, namely the $\log$ of dividend price ratio, the response of prices is again sizable and persistent (not shown).

As a final check we have included the commodity price index used by Christiano, Eichenbaum and Evans (1999), which is a composite index of leading indicators for inflation. The inclusion of this variable also makes our benchmark VAR more in line with the standard VARs estimated in the literature on monetary policy. The last column of Figure 6c displays the results: the impulse response functions to an LM shock are not affected and the commodity price index rises sizably.

Non-Financial Variables A simplifying assumption of the standard framework of Section 2 is to abstract from investment and government consumption as additional determinants of aggregate demand, and from wages and unemployment as determinants of inflation. To check whether these simplifications are somehow responsible for our results, we have added investment and government consumption in the first two columns of Figure 6d, both ordered in the VAR before the interest rate. This additional attempt did not produce any significant change in the benchmark responses. The impulse responses reported in the last two columns also suggest that the inclusion of wages or unemployment does not affect the overall picture of Section $3 .^{13}$

In sum, our robustness checks indicate that unpredictable shifts in broad monetary aggregates have significant and robust effects on the dynamics of output, prices and interest rates. The effects on prices are consistently the largest.

\footnotetext{
${ }^{13}$ Investment is measured as the log of total private investment, s.a. Government consumption is the log of U.S. government consumption expenditure and gross investments, sa. Wages is the log of nonfarm business sector compensation per hour, s.a. Unemployment is the civilian unemployment rate, sa.
} 


\subsection{Identification}

The sample period used to estimate the benchmark VAR of Section 3 includes a long period in which the Fed adopted intermediate targets for monetary aggregates (1970-1993). Though most economists believe that monetary targets were never the most pressing concern at the Fed, practical considerations may suggest to include money in the central bank's reaction function. ${ }^{14}$ So far, the identification scheme used to isolate LM shocks does not permit the Fed to react to monetary aggregates within the period. Though reasonable, this assumption is not compelling and, should it be incorrect, the LM shocks retrieved by the Cholesky decomposition would be likely to be a mixture of LM and monetary policy shocks.

To control for this possibility, we next identify monetary policy shocks and LM shocks without imposing that the federal funds rate does not respond to monetary aggregates within the quarter. For this purpose, we use the same VAR of Section 3 but move from a fully recursive structure to a structural identification. The structural model is described by:

$$
B_{0} Z_{t}=B_{1} Z_{t-1}+\ldots+B_{1} Z_{t-p}+v_{t}
$$

where $Z_{t}^{\prime}=\left\{x_{t}, y_{t}, p_{t}, i_{t}, m_{t}\right\}$, is the vector of endogenous variables. $B_{i}$ are $5 \times 5$ matrices with $B_{0}$ having unity diagonal elements, and $v_{t}^{\prime}=\left\{v_{t}^{d}, v_{t}^{n}, v_{t}^{s}, v_{t}^{p}\right.$, $\left.v_{t}^{l}\right\}$ is the vector of structural innovations with diagonal covariance matrix. Since the relation between the structural innovations $v_{t}$ and the associated reduced form residuals $u_{t}$ is given by:

$$
u_{t}=B_{0}^{-1} v_{t},
$$

monetary policy and LM shocks are identified by imposing restrictions on the $B_{0}$ matrix. Specifically, we impose the following: (1) the interest rate responds contemporaneously to output gap and prices, but not to output; (2) money responds contemporaneously to output, interest rate and prices, but not to output gap. These two sets of restrictions (in fact either one would be sufficient) provide a way to distinguish monetary policy shocks from LM shocks, which is novel in the literature. The first restrictions amount to imposing that the Fed follows a Taylor-type interest rate rule. The restrictions on money, instead, are motivated by a standard money demand equation. As in the previous section, the remaining shocks are left unidentified and we only require that capacity, GDP and prices are not contemporaneously affected by monetary policy and LM shocks.

The estimated contemporaneous responses are reported in Table 2a. A few results stand out. First, the overidentifying restriction is easily accepted: the $p$-value for the associated $\chi(1)$ test is 0.54 . Second, the estimated coefficients

\footnotetext{
${ }^{14}$ Leeper and Zha (2001) have recently argued that the fact that the Fed now ignores money does not imply that money never had a role in the past for formulating monetary policy. They also present evidence for U.S. data that an interest rate rule that responds only to the growth rate of money is empirically similar to an interest rate rule that responds to inflation and output gap.
} 
have the predicted sign, with the exception of the coefficient of prices in the money equation, which indicates that nominal money holdings do not respond immediately to price variations in order to keep real money holdings constant. The federal funds rate responds positively to both inflation and the output gap, while demand for money increases with the level of real output and decreases with the nominal interest rate. The interest rate, however, does not react positively to money: the coefficient is insignificant and has the wrong sign, suggesting that only a liquidity effect is at work. In fact, as shown in Table $2 \mathrm{~b}$, if we force the coefficient $B_{0}[4,5]$ (the contemporaneous response of $i$ to $m$ ) to zero, the coefficient $B_{0}[5,4]$ (the contemporaneous response of $m$ to $i$ ) becomes slightly larger and significant, which suggests the absence of a liquidity puzzle. Similar results are obtained if annual inflation and real money balances are used instead of prices and money, and if the coefficient $B_{0}[4,2]$ (contemporaneous response of $i$ to $y$ ) is left unrestricted. ${ }^{15}$

The impulse response functions of this SVAR, plotted in Figure 3 are indistinguishable from those of an exactly identified triangular VAR. For example, the responses to an LM shock (the second column) are identical to those of Figure 1, while the responses to a monetary policy shock (the first column) are rather standard: after a contractionary monetary policy shock (a rise in the federal funds rate), output gap has a hump-shaped response; prices initially respond very slowly but persistently decline afterwards; and money decreases upon impact and for several quarters. ${ }^{16}$

There are two additional results worth mentioning. The first, reported in Figure 4 , is that there are no appreciable differences in the impulse response functions of output, output gap and prices following a monetary policy shock, if money is excluded from the VAR. This finding suggests that the inclusion of money in the VAR does not alter the transmission of monetary policy shocks to the economy. Rather, money seems to play an independent role for prices and output.

The second result, reported in Figure 5, is that impulse responses remain almost unchanged if we use the same contemporaneous restrictions used above (with $B_{0}[4,5]$ set to zero), plus the additional constraints that lags of GDP and M2 do not enter the interest rate equation. The impulse responses from the constrained and unconstrained SVAR are nearly identical, which cautiously suggests that a standard dynamic Taylor rule adequately approximates the monetary authority reaction function. ${ }^{17}$ This last result does not mean that there is strong evidence that the monetary authorities were not responding at all to money, but indicates that the bulk of movements in the interest rate, following an LM shock, may simply reflect the Fed's response to output and inflation.

\footnotetext{
${ }^{15}$ In this latter case the estimated coefficient of $B_{0}[4,2]$ is not statistically significant (its $p$-value is 0.54 ), supporting our assumption that the monetary authority does not react to output once we have conditioned on the output gap.

${ }^{16}$ See among others Christiano, Eichenbaum and Evans (1999) or Leeper, Sims and Zha (1996) for similar results

${ }^{17}$ When we compare the unrestricted and restricted VAR with standard information criteria, both the Schwarz criterion and the Hannan and Quinn favor the restricted VAR, while the Akaike favors the uncostrained one.
} 


\section{$5 \quad$ F-tests and block-exogeneity tests}

So far we have discussed the empirical relationship between monetary aggregates, output and prices by means of impulse response functions. We have found strong evidence that money affects the dynamics of prices and some evidence that money also influences the dynamics of output. Moreover, we have observed that these results arise if we use broad monetary aggregates (M2 or M3) rather than a narrow measure of money (M0 or M1).

A more traditional approach, extensively used in the empirical literature, is to perform $F$-tests on reduced form equations. This literature is large but has not reached definitive conclusions. For example, Sims (1972) using a bivariate VAR demonstrates that money (M0 and M1) Granger causes nominal GDP. Christiano and Ljungqvist (1988) find that M1 helps predicting nominal GDP and Stock and Watson (1989) reach similar conclusions after controlling for inflation and interest rates. Conversely, Bernanke and Blinder (1992) show that interest rates absorb the predictive power of money (M1 and M2) for output and prices in a multivariate system, and Friedman and Kuttner $(1992,1996)$ and Estrella and Mishkin (1997), argue that the predictive content of monetary aggregates (monetary base, M2 and M1) for inflation and output has diminished since the 80's, due to the erratic behavior of money velocity. Opposite conclusions arise in Feldstein and Stock (1993), who show that money (M2) is a significant forecaster of nominal GDP, and in Cheung and Fujii (2001), who correct the tests used by Friedman and Kuttner for heteroskedasticity, and conclude that the effect of money on output becomes significant, though not sizable.

How can we reconcile our results with the contrasting evidence based on single equation $F$-tests? Part of the problem associated with $F$-tests is that they are frequently interpreted as tests of block-exogeneity, that is, as tests that "money does not help forecasting output and/or prices in a multivariate system". This interpretation, however, is not correct if the system has more than two variables. When asking whether money has a role in a multivariate system, it is more appropriate to run a joint test on all equations rather than on a single equation.

In a bivariate system with, say, output $(y)$ and money $(m)$, block-exogeneity can be tested by regressing $y$ on lags of itself and lags of $m$, and testing the null that all lags of $m$ are redundant. But a single equation $F$-test is no longer an adequate test of block-exogeneity in a system with more than two variables. If our system of equations includes an additional variable, say prices $(p)$, and we regress $y$ on lags of $y, p$ and $m$, zero coefficients on lags of $m$ only imply that $m$ does not help in forecasting $y$ one step ahead, but do not prevent $m$ from being helpful in forecasting $y$ through $p$ at longer horizons, unless we can also show that lags of $m$ are redundant for $p .{ }^{18}$

\footnotetext{
${ }^{18}$ More formally, a vector of variables $Z$ is block-exogenous in the time series sense with respect to a money, $m$, if $m$ does not help in improving (in the RMSE sense) the forecast at any horizon of any variable in $Z$ that is based on lagged values of all the elements of $Z$ alone (Hamilton, 1994, page 309). A necessary and sufficient condition for block-exogeneity is that
} 
The following example illustrates the limits of standard, single equation $F$ tests. Assume that the data generating process is given by a model which incorporates, in a simple framework, the common New Keynesian assumption that interest rate movements influence inflation only through their effects on output:

$$
\begin{aligned}
\pi_{t} & =\pi_{t-1}+\kappa x_{t-1}+\epsilon_{t}^{s} \\
x_{t} & =-\sigma\left(i_{t-1}-\pi_{t-1}\right)+\epsilon_{t}^{d} \\
i_{t} & =f_{\pi} \pi_{t}+f_{x} x_{t}+\epsilon_{t}^{p},
\end{aligned}
$$

where $\pi$ is the inflation rate, $x$ is the output gap, and $i$ is a short interest rate. Suppose we estimate the following equation for the inflation rate:

$$
\pi_{t}=\delta_{\pi} \pi_{t-1}+\delta_{x} x_{t-1}+\delta_{i} i_{t-1}+\epsilon_{t}^{s},
$$

and run an $F$-test for the null hypothesis that $\delta_{i}$ is zero. Since the null is true, it is unlikely to be rejected. However, it would be wrong to infer from this $F$-test that the interest rate is not useful in forecasting inflation at any horizon. For this conclusion to be valid, $\sigma$ should also be zero. Something similar could happen with money: even if $F$-tests consistently concluded that money does not belong in a reduced-form equation for output, it would still be possible that money affects output indirectly, through other variables (such as prices and interest rates) which in turn influence output.

In Table 4 we report $p$-values for the null hypothesis that variables in several VARs are block-exogenous with respect to M2, as suggested by New Keynesian models. In the upper panel, the test is conducted for the benchmark VAR(4) of Section 3, estimated both with all variables in levels and with real GDP, CPI and M2 in differences. The expanded VARs of Section 4.3 are considered in the lower parts of the panel. The $p$-values are typically small, a result in line with the impulse responses reported in previous sections. ${ }^{19}$ Moreover, the null of block-exogeneity is always rejected at $5 \%$ on the 1980-2001 sub-sample.

The overall evidence from block-exogeneity tests helps explaining why impulse response functions and single equation $F$-tests may produce different results.

when $m$ is ordered after $Z$ in a Cholesky decomposition, the impulse response functions of all elements of $Z$ to a shock in $m$ are flat (Lutkepohl, 1993, Proposition 2.2). Incidentally, this is the strategy adopted in Section 3.

${ }^{19}$ The $p$-values are from a chi-square distribution, and from a chi-square with the conservative modification suggested by Sims (1980). The VAR is also estimated in first differences to account for the potential problem of the non standard distribution that the $F$-test takes when variables have unit roots (see Sims, Stock and Watson, 1990). 


\section{Conclusion}

The New Keynesian framework predicts that knowledge of the quantity of money is not needed to determine the path of output, prices and interest rates. The empirical research has reached contradicting results on this issue. While the literature works either with a specific model or with a single reduced-form equation, this paper examines the effects of shocks to monetary aggregates using an identified VAR. An important feature of our methodology is that the identifying restrictions we use are directly implied by a broad class of models for monetary policy analysis that assign a residual role to money. Contrary to the predictions of the theory, our results suggest that shocks to monetary aggregates contain information on the future path of output and (especially) of prices. The results are robust to changes in VAR specification that account for extensions of the basic New Keynesian model. The results are much sharper for broad monetary aggregates (M2 or M3) than for narrow money.

These findings seem robust enough to suggest that current models of monetary policy may neglect an important determinant of output and inflation dynamics by assuming away any reference to monetary aggregates. We find that a clear-cut prediction of widely used models for policy analysis is decisively rejected by empirical tests. We do not, however, endorse or provide an alternative theoretical framework that could account for this finding. For this reason we have deliberately chosen to dub shocks to monetary aggregates "LM shocks" and avoided giving them a structural interpretation, despite the fact that our estimates retrieve a sensible money demand equation. Our hope is that further research will pick up the challenge of accounting for the results of this paper. 


\section{A Appendix: State space representation}

Consider the structural model of Section 2:

$$
\begin{aligned}
\pi_{t} & =\beta E_{t} \pi_{t+1}+\kappa x_{t}+\epsilon_{t}^{s} \\
x_{t} & =E_{t} x_{t+1}-\sigma\left(i_{t}-E_{t} \pi_{t+1}\right)+\epsilon_{t}^{d} \\
i_{t} & =f_{\pi} \pi_{t}+f_{x} x_{t}+\epsilon_{t}^{p} \\
m_{t} & =h y_{t}-\eta i_{t}+\epsilon_{t}^{l}
\end{aligned}
$$

and define with $\epsilon_{t}=\left[\begin{array}{lllll}y_{t}^{n} & \epsilon_{t}^{s} & \epsilon_{t}^{d} & \epsilon_{t}^{p} & \varepsilon_{t}^{l}\end{array}\right]^{\prime}$ the vector of predetermined variables with orthogonal innovations $v_{t}=\left[\begin{array}{lllll}v_{t}^{n} & v_{t}^{s} & v_{t}^{d} & v_{t}^{p} & v_{t}^{l}\end{array}\right]^{\prime}$ and with $X_{t}=\left[\begin{array}{lll}y_{t} & \pi_{t} & m_{t}\end{array}\right]^{\prime}$ the vector of forward looking variables. The dynamics of the model can then be written as

$$
\begin{aligned}
\mathbf{A}\left[\begin{array}{c}
\epsilon_{t+1} \\
E_{t} X_{t+1}
\end{array}\right] & =\mathbf{B}\left[\begin{array}{c}
\epsilon_{t} \\
X_{t}
\end{array}\right]+\mathbf{C} i_{t}+\left[\begin{array}{c}
v_{t+1} \\
0_{n_{X} \times 1}
\end{array}\right] \\
i_{t} & =-\mathbf{F}\left[\begin{array}{c}
\epsilon_{t} \\
X_{t}
\end{array}\right],
\end{aligned}
$$

where the matrices of structural parameters $\mathbf{A}, \mathbf{B}$ and $\mathbf{C}$ are given by

$$
\begin{gathered}
\mathbf{A}=\left[\begin{array}{ccccccc}
I_{5 \times 1} & \multicolumn{5}{c}{0_{5 \times 3}} \\
\hline & & -1 & -\sigma & 0 \\
& 0_{3 \times 5} & 0 & -\beta & 0 \\
& & 0 & 0 & 0
\end{array}\right] \\
\mathbf{B}=\left[\begin{array}{ccccc|ccc}
\rho_{n} & 0 & 0 & 0 & 0 & 0 & 0 & 0 \\
0 & \rho_{s} & 0 & 0 & 0 & 0 & 0 & 0 \\
0 & 0 & \rho_{d} & 0 & 0 & 0 & 0 & 0 \\
0 & 0 & 0 & \rho_{p} & 0 & 0 & 0 & 0 \\
0 & 0 & 0 & 0 & \rho_{l} & 0 & 0 & 0 \\
\hline\left(1-\rho_{n}\right) & 0 & 1 & 0 & 0 & 1 & 0 & 0 \\
-\kappa & 1 & 0 & 0 & 0 & \kappa & -1 & 0 \\
0 & 0 & 0 & 0 & 1 & h & 0 & -1
\end{array}\right] \\
\mathbf{C}=\left[\begin{array}{ccccccccc}
0 & 0 & 0 & 0 & 0 & -\sigma & 0 & -\eta
\end{array}\right]^{\prime},
\end{gathered}
$$

and the policy rule $\mathbf{F}$ is:

$$
\mathbf{F}=\left[\begin{array}{llllllll}
f_{x} & 0 & 0 & -1 & 0 & -f_{x} & -f_{\pi} & 0
\end{array}\right]^{\prime}
$$




\section{References}

[1] Ball, Lawrence (1997), "Efficient Rules for Monetary Policy" NBER Working Paper No. 5952.

[2] Bernanke, Ben S., and Alan S. Blinder (1992), "The Federal Fund Rate and the Channels of Monetary Transmission", American Economic Review, 82(4), 901-921.

[3] Bernanke, Ben S., and Ilian Mihov (1998), "Measuring Monetary Policy", Quarterly Journal of Economics, 113(3), 869-902.

[4] Cheung, Yin-Wong, and Eiji Fujii (2001), "A Note on the Money-Output Causality Tests", Oxford Bulletin of Economic and Statistics, 63,

[5] Christiano, Lawrence J., and Lars, Ljungqvist (1988), "Money Does Granger-Cause Output in the Bivariate Money-Output Relation", Journal of Monetary Economics, 22, 217-36

[6] Christiano, Lawrence J., Martin Eichenbaum and Charles L. Evans (1999), "Monetary Policy Shocks: What Have We Learned and to What End?", in Handbook of Macroeconomics, ed. by J.B. Taylor, and M. Woodford, Vol. 1A, 65-148. Elsevier Science, Amsterdam.

[7] Clarida, Richard, Jordi Gali and Mark Gertler (1999), "The Science of Monetary Policy", Journal of Economic Literature, 37, 1661-1707.

[8] Doan, Thomas. A., (1992), RATS User's manual, Estima.

[9] Estrella, Arturo and Frederic. S. Mishkin (1997), "Is There a Role for Monetary Aggregates in the Conduct of Monetary Policy," Journal of Monetary Economics 40(2), 279-304.

[10] Feldstein, Martin and James H. Stock (1993), "The Use of Monetary Aggregates to Target Nominal GDP", in Monetary Policy, ed. by N. Gregory Mankiw, pp.7-70, University of Chicago Press.

[11] Friedman, Benjamin M. and Kenneth N. Kuttner (1992), " Money, Income, Prices and Interest Rates," American Economic Review, 82, 472-492.

[12] Friedman, Benjamin M. and Kenneth N. Kuttner (1996), " A Price Target fo U.S. Monetary Policy, Lessons from the Experience with Money Growth Targets", Brooking Papers on Economic Activity, Vol. 1, 77-125

[13] Gerlach, Stephan and Frank Smets (1995), " The Monetary Transmission Mechanism: Evidence form the G-7 Countries," in Financial Structure and the Monetary Policy Transmission Mechanism, Bank of International Settlements (Basle, Switzerland), 188-224. 
[14] Giordani, Paolo (2000), "An Alternative Explanation of the Price Puzzle," Working Paper, Stockholm School of Economics, available at www.hhs.se/personal/Giordani.

[15] Hamilton, James D., (1994), "Time Series Analysis," Princeton University Press, Princeton.

[16] Ireland, Peter N., (2001) "Money's Role in the Monetary Business Cycle", NBER Working Paper No, 8115.

[17] Leeper, Eric M., Christopher A. Sims and Tao Zha (1996): "What Does Monetary Policy Do", Brooking Papers on Economic Activity, Vol. 2, 1-63.

[18] Leeper, Eric M., and Tao Zha (2001), "Assessing Simple Rules: A View from a Complete Macro Model," Federal Reserve Bank of St. Louis Review, 83, July/August, 83-110.

[19] Lutkepohl, Helmut (1993). "Introduction to Multiple Time Series Analysis," Springer-Verlag.

[20] McCallum, Bennet T. (2001), "Monetary Policy Analysis in Models without Money", NBER Working Paper No. 8174.

[21] McCallum, Bennet T., and Edward Nelson (1999), "An Optimizing IS-LM Specification for Monetary Policy and Business Cycle Analysis," Journal of Money Credit, and Banking, 31, 296-316.

[22] Meltzer, Allan H. (1999), "The Transmission Process", in Deutsche Bundesbank, The Monetary Transmission Process: Recent Developments and Lessons for Europe, MacMillan, London.

[23] Nelson, Edwards (2002), "Direct Effects of Base Money on Aggregate Demand: Theory and Evidence", Journal of Monetary Economics, 49, 687708.

[24] Reifshneider, David, Robert Tetlow, and John Williams (1999), "Aggregate Disturbances, Monetary policy and Macroeconomy: The FRB/US Perspective," Federal Reserve Bulletin, 75, 244-254.

[25] Rotemberg, Julio J. and Michael Woodford (1997), "An OptimisationBased Econometric framework for the Evaluation of Monetary Policy," NBER Macroeconomics Annual, 297-346. Cambridge, MA: MIT Press.

[26] Rudebusch, Glenn D., and Lars E.O. Svensson (2002), "Eurosystem Monetary Targeting: Lessons form U.S. Data" , European Economic Review 46, 417-442.

[27] Schorfheide, Frank (2000), "Loss Function Based Evaluation of DSGE Models" , Journal of Applied Econometrics 16, 645-670. 
[28] Sims, Christopher A., (1972), "Money, Income, and Causality," American Economic Review, 62, 540-52.

[29] Sims, Christopher A., (1980), "Macroeconomics and Reality," Econometrica, 48, 1-48.

[30] Sims, Christopher A., James. H. Stock and Mark. W. Watson (1990), "Inference in Linear Time Series Models with Some Unit Roots," Econometrica, 58, 113-144.

[31] Söderlind, Paul, (1999), "Solution and Estimation of RE Macromodels with Optimal Policy," European Economic Review, 43, 813-823.

[32] Stock, James. H., and Mark. W. Watson (1989), "Interpreting the Evidence on Money-Income Causality", Journal of Econometrics, 40(1), 161-181.

[33] Stock, James. H., and Mark. W. Watson, (2001), "Forecasting Output and Inflaton: The Role of Asset Prices", mimeo Princeton University

[34] Svensson, Lars E.O., (1997), "Inflation Forecast Targeting: Implementing and Monitoring Inflation Targets", European Economic Review, 41, 11111146.

[35] Svensson, Lars. E.O., (2002), "What Is Wrong with Taylor Rules? Using Judgment in Monetary Policy through Targeting Rules," Journal of Economic Literature, forthcoming.

[36] Taylor, John B. (1999), "The Robustness and Inefficiency of Monetary Policy Rules as Guidelines for Interest Rate Setting by the European Central Bank," Journal of Monetary Economics, 43 pp. 655-679

[37] Woodford, Michael (2002), Interest and Prices: Foundations of a Theory of Monetary Policy. Princeton University Press, forthcoming. 
Table 1: Variance Decomposition

Benchmark VAR(4)

Sample Period: 1966:1-2001:3

\begin{tabular}{cccccc}
\hline \hline Period & Capacity & Real GDP & CPI & FF Rate & M2 \\
\hline & & & & & \\
0 & 0 & 0 & 0 & 0 & 82 \\
2 & 4 & 3 & 4 & 2 & 65 \\
4 & 12 & 7 & 10 & 11 & 59 \\
8 & 10 & 5 & 23 & 24 & 54 \\
16 & 20 & 13 & 43 & 32 & 51 \\
\hline \hline
\end{tabular}

Note: \% of forecast error variance due to LM shocks.

Table 2a: Estimated contemporaneous coefficients $\operatorname{SVAR}(4)$

Sample period: 1966:1-2001:3

\begin{tabular}{|c|c|c|c|c|c|c|c|}
\hline & & $B_{0}$ & & & $u_{t}$ & $\overline{\bar{P}}=$ & $v_{t}$ \\
\hline$x$ & 0 & 0 & 0 & 0 & $u_{x}$ & & {$\left[v_{x}\right.$} \\
\hline$x$ & $x$ & 0 & 0 & 0 & $u_{y}$ & & $v_{y}$ \\
\hline$x$ & $x$ & $x$ & 0 & 0 & $u_{p}$ & $=$ & $v_{p}$ \\
\hline $\begin{array}{c}-0.46^{* * *} \\
(0.06)\end{array}$ & 0 & $\begin{array}{c}-0.52^{* *} \\
(0.19)\end{array}$ & 1 & $\begin{array}{l}0.22 \\
(0.22)\end{array}$ & $u_{i}$ & & $v_{i}$ \\
\hline 0 & $\begin{array}{c}-0.19^{* * *} \\
(0.07)\end{array}$ & $\begin{array}{l}0.23 \\
(0.16)\end{array}$ & $\begin{array}{l}0.14 \\
(0.11)\end{array}$ & 1 & $u_{m}$ & & $v_{m}$ \\
\hline
\end{tabular}

Note: Standard errors in parenthesis. ${ }^{* * *}$ denotes significance at $1 \%$ level, $* *$ denotes significance at $5 \% . \times$ denotes freely estimated coefficients.

The $p$-value for the test of overidentifying restriction $\chi(1)$ is 0.54

Table 2b: Estimated contemporaneous coefficients $\operatorname{SVAR}(4)$

Sample period: 1966:1-2001:3

\begin{tabular}{|c|c|c|c|c|c|c|c|}
\hline & & $B_{0}$ & & & $\overline{u_{t}}$ & $=$ & $v_{t}$ \\
\hline$x$ & 0 & 0 & 0 & 0 & $u_{x}$ & & $v_{x}$ \\
\hline$x$ & $x$ & 0 & 0 & 0 & $u_{y}$ & & $v_{y}$ \\
\hline$x$ & $x$ & $x$ & 0 & 0 & $u_{p}$ & $=$ & $v_{p}$ \\
\hline $\begin{array}{c}-0.46^{* * *} \\
(0.06)\end{array}$ & 0 & $\begin{array}{c}-0.60^{* *} \\
(0.19)\end{array}$ & 1 & 0 & $u_{i}$ & & $v_{i}$ \\
\hline 0 & $\begin{array}{c}-0.22^{* * * *} \\
(0.06)\end{array}$ & $\begin{array}{l}0.14 \\
(0.14)\end{array}$ & $\begin{array}{c}0.23^{* * *} \\
(0.05)\end{array}$ & 1 & $u_{m}$ & & $v_{m}$ \\
\hline
\end{tabular}

Note: See Table $2 \mathrm{a}$

The $p$-value for the test of overidentifying restriction $\chi(2)$ is 0.43 
Table 3: Block Exogenity for $M 2$

\begin{tabular}{|c|c|c|c|c|}
\hline & \multicolumn{4}{|c|}{ Sample Period } \\
\hline & \multicolumn{2}{|c|}{ 1966:1-2001:3 } & \multicolumn{2}{|c|}{ 1980:1-2001:3 } \\
\hline & p-value & Sims corr. & $\mathrm{p}$-value & Sims corr. \\
\hline & \multicolumn{4}{|c|}{ Benchmark VAR } \\
\hline Levels and Diff & 0.024 & 0.073 & 0.001 & 0.017 \\
\hline \multirow[t]{2}{*}{ Levels } & 0.000 & 0.003 & 0.001 & 0.016 \\
\hline & \multicolumn{4}{|c|}{ Benchmark + Long Interest Rate } \\
\hline Levels and Diff & 0.003 & 0.023 & 0.000 & 0.018 \\
\hline \multirow[t]{2}{*}{ Levels } & 0.000 & 0.002 & 0.000 & 0.012 \\
\hline & \multicolumn{4}{|c|}{ Benchmark + Default Spread } \\
\hline Levels and Diff & 0.065 & 0.211 & 0.000 & 0.020 \\
\hline \multirow[t]{2}{*}{ Levels } & 0.000 & 0.001 & 0.001 & 0.026 \\
\hline & \multicolumn{4}{|c|}{ Benchmark + S \& P 500} \\
\hline Levels and Diff & 0.057 & 0.182 & 0.001 & 0.029 \\
\hline \multirow[t]{2}{*}{ Levels } & 0.023 & 0.095 & 0.001 & 0.028 \\
\hline & \multicolumn{4}{|c|}{ Benchmark + Commodity Price Index } \\
\hline Levels and Diff & 0.035 & 0.144 & 0.000 & 0.000 \\
\hline \multirow[t]{2}{*}{ Levels } & 0.000 & 0.000 & 0.000 & 0.000 \\
\hline & \multicolumn{4}{|c|}{ Benchmark + Investments } \\
\hline Levels and Diff & 0.009 & 0.052 & 0.001 & 0.033 \\
\hline \multirow[t]{2}{*}{ Levels } & 0.000 & 0.003 & 0.000 & 0.001 \\
\hline & \multicolumn{4}{|c|}{ Benchmark + Government Consumption } \\
\hline Levels and Diff & 0.001 & 0.007 & 0.001 & 0.039 \\
\hline \multirow[t]{2}{*}{ Levels } & 0.000 & 0.001 & 0.000 & 0.001 \\
\hline & \multicolumn{4}{|c|}{ Benchmark + Wages } \\
\hline Levels and Diff & 0.037 & 0.135 & 0.001 & 0.042 \\
\hline \multirow[t]{2}{*}{ Levels } & 0.015 & 0.069 & 0.000 & 0.016 \\
\hline & \multicolumn{4}{|c|}{ Benchmark + Unemployment } \\
\hline Levels and Diff & 0.006 & 0.038 & 0.000 & 0.014 \\
\hline Levels & 0.003 & 0.023 & 0.000 & 0.000 \\
\hline
\end{tabular}

Note: $p$-values are from a chi-squared distribution, and with conservative correction suggested by Sims. Benchmark VAR includes: output gap, real output, prices and interest rate. The null is that the block of variables are exogenous for M2. Under the row Levels, all variables are estimated in levels. In row Levels and Diff the interest rates and capacity are in levels and all other variables are in first difference. 
copacity to LM shock

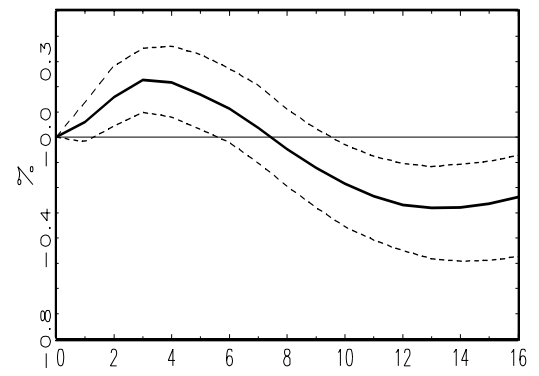

CPI to LV shock

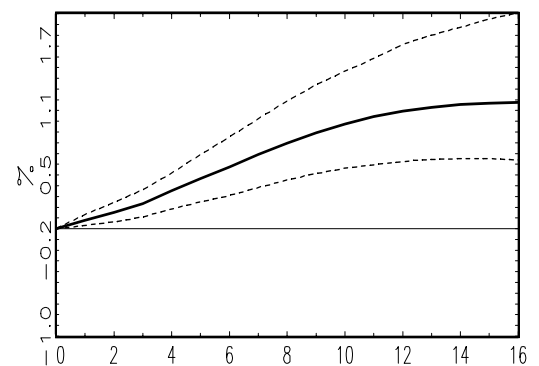

M2 to LM shock

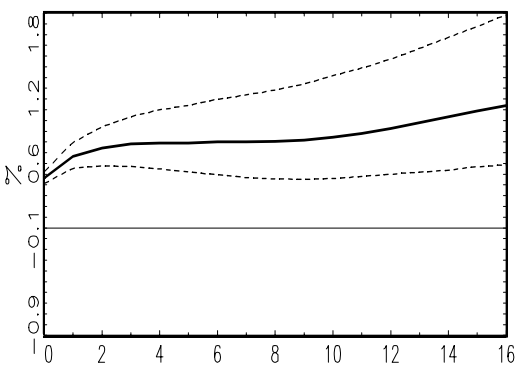

real GDP to LM shock

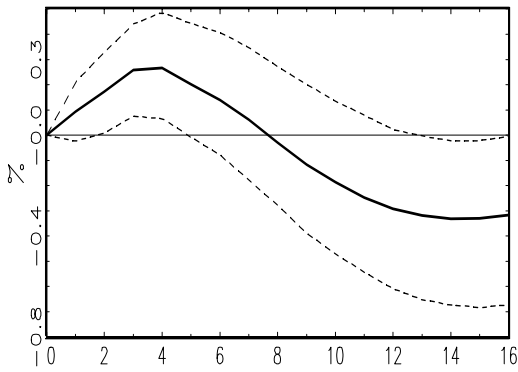

funds rate to LM shock

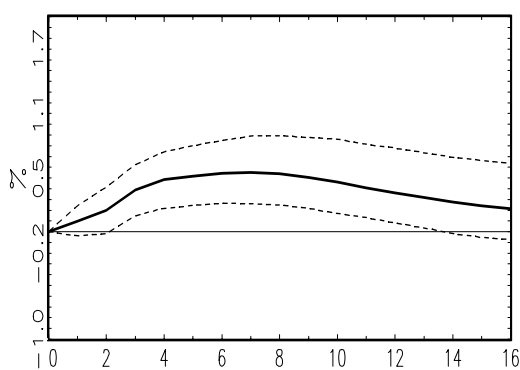




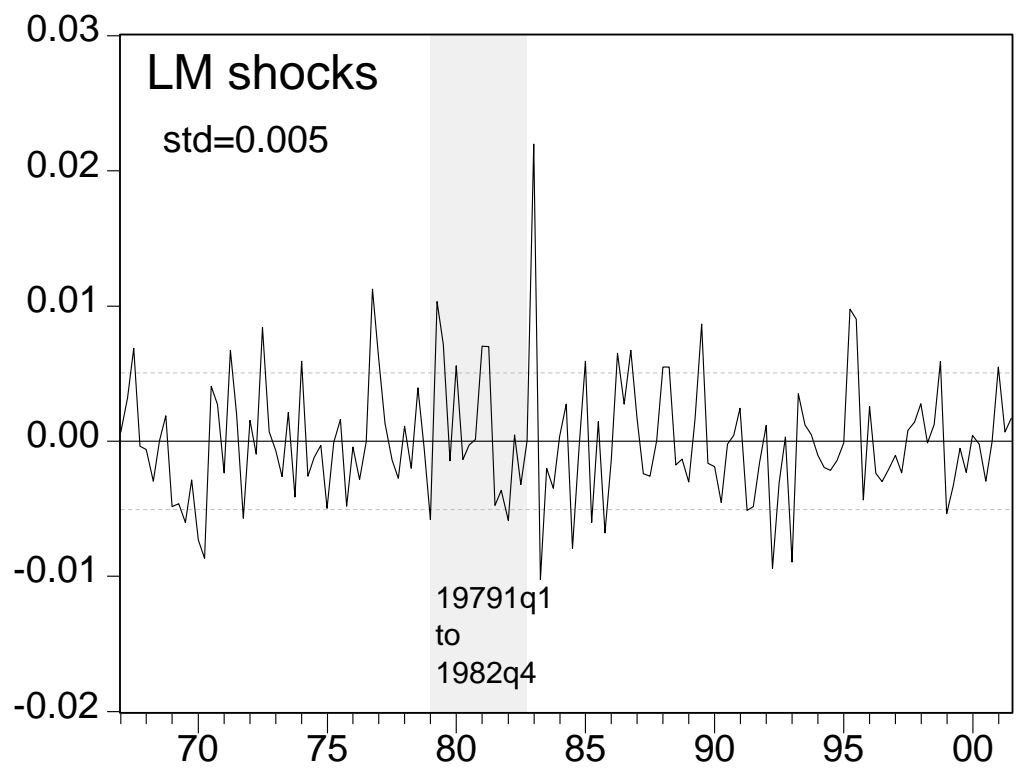

Figure 2: LM shocks from benchmark VAR(4) of Section 3. 
capacity to MP shock

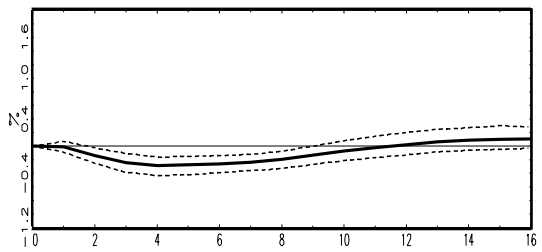

real GDP to MP shock

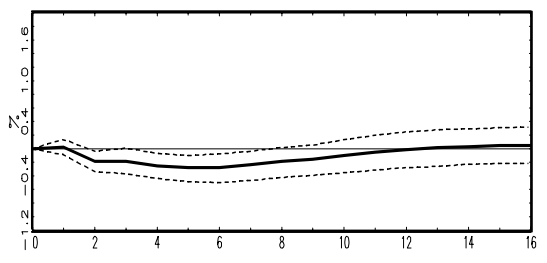

CPI to MP shock

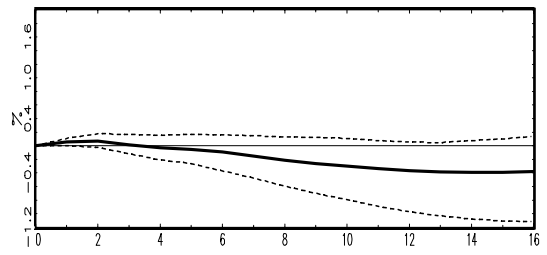

funds rote to MP shock
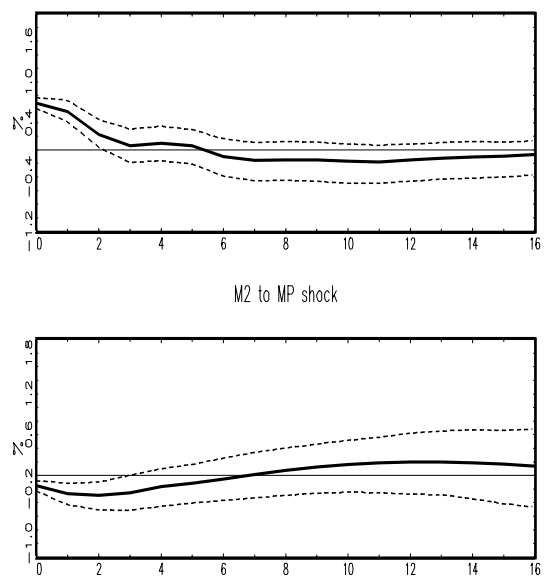

copocity to LM shock

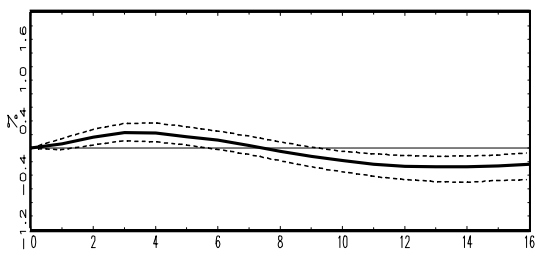

real GDP to LM shock

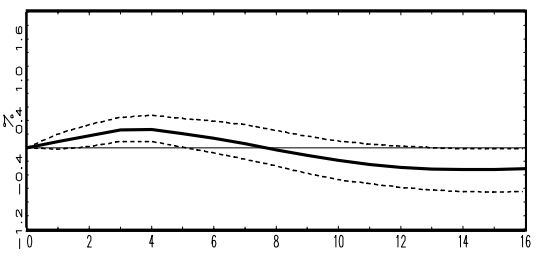

CPI to LM shock

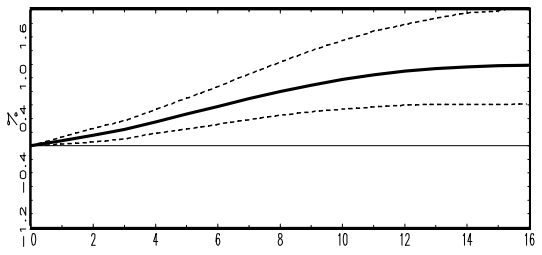

funds rote to LM shock

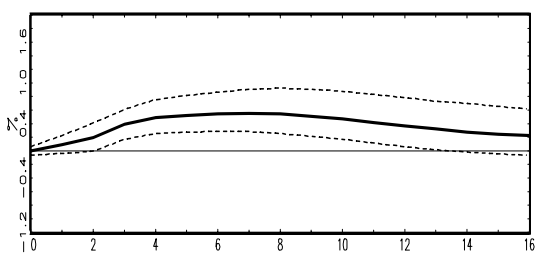

W2 to LM shock

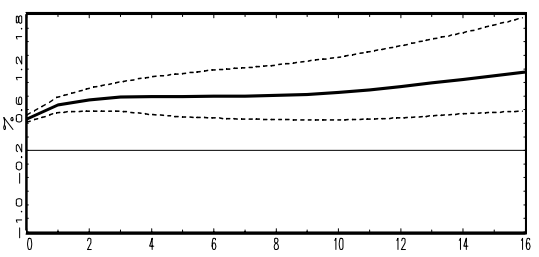

Figure 3: Impulse response functions to monetary policy shocks and LM shocks in the SVAR of Section 4.4, with $95 \%$ error bands (thin dashed line). 
capacity to MP shock
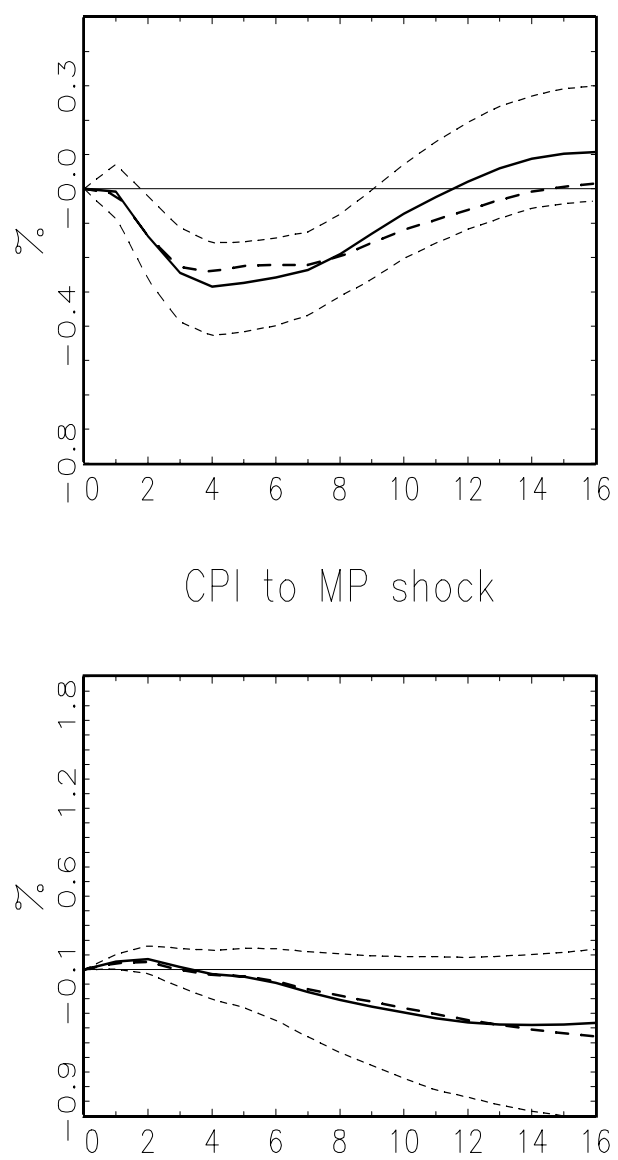

real GDP to MP shock
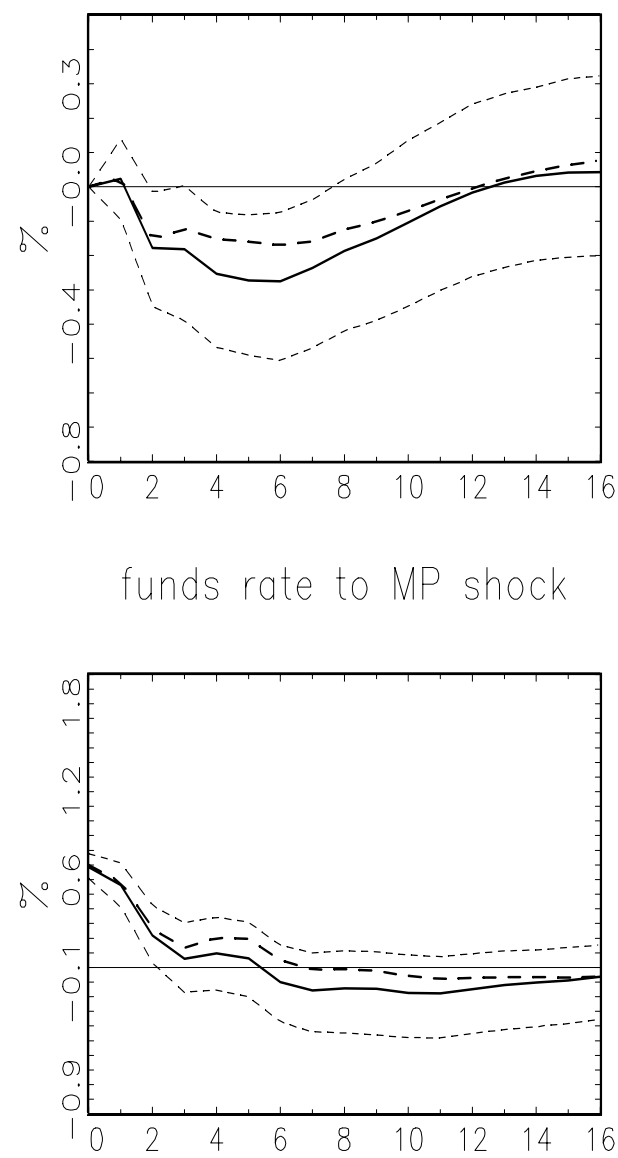

Figure 4: Impulse response functions to a one-std monetary policy shock in the SVAR(4) of Section 4.4 (continuous line), and in a VAR(4) that excludes M2 (thick dashed line). 95\% error bands (thin dashed line) refer to the SVAR. 
copocity to MP shock

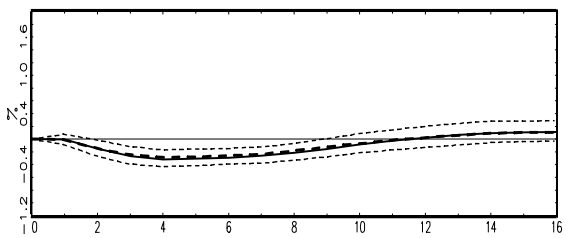

reol GDP to MP shock

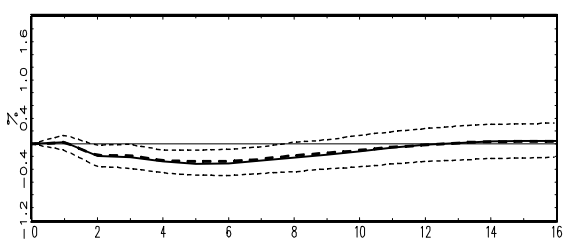

CPI to MP shock

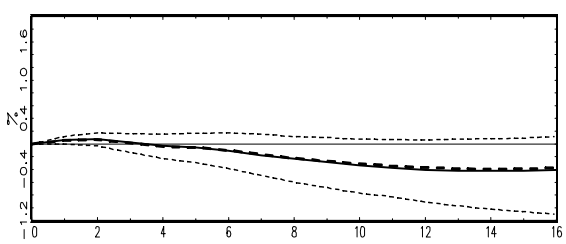

funds rate to NP shock
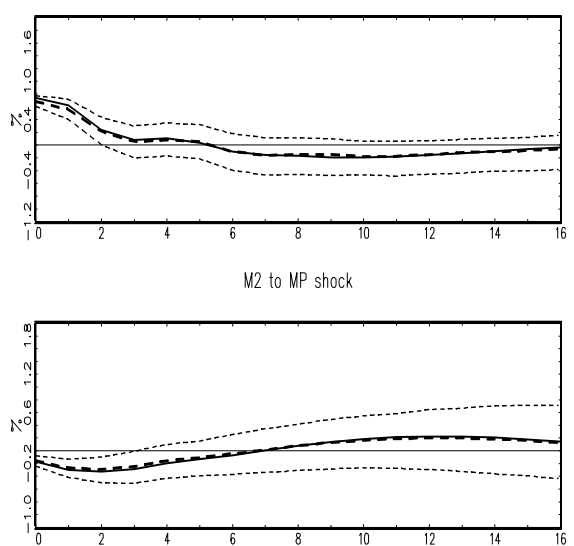

copacity to LM shock

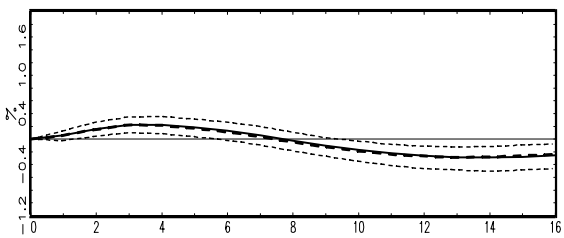

real GDP to LM shock

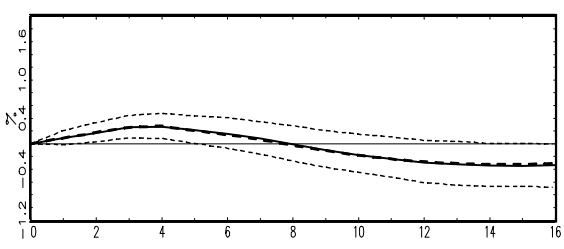

CPI to LM shock

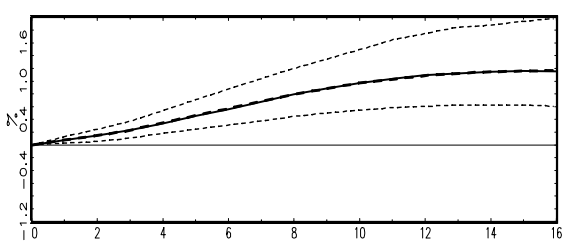

unds rate to LM shoc
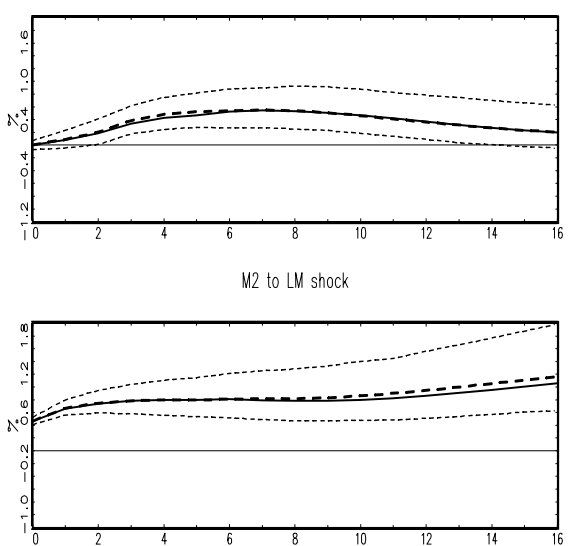

Figure 5: Impulse response functions to monetary policy shocks and LM shocks in the two SVAR(4) of Section 4.4: with unconstrained lags (continuous line), and with no lags of GDP and M2 in the interest rate equation (thick dashed line). $95 \%$ error bands (thin dashed line) refer to the first SVAR. 

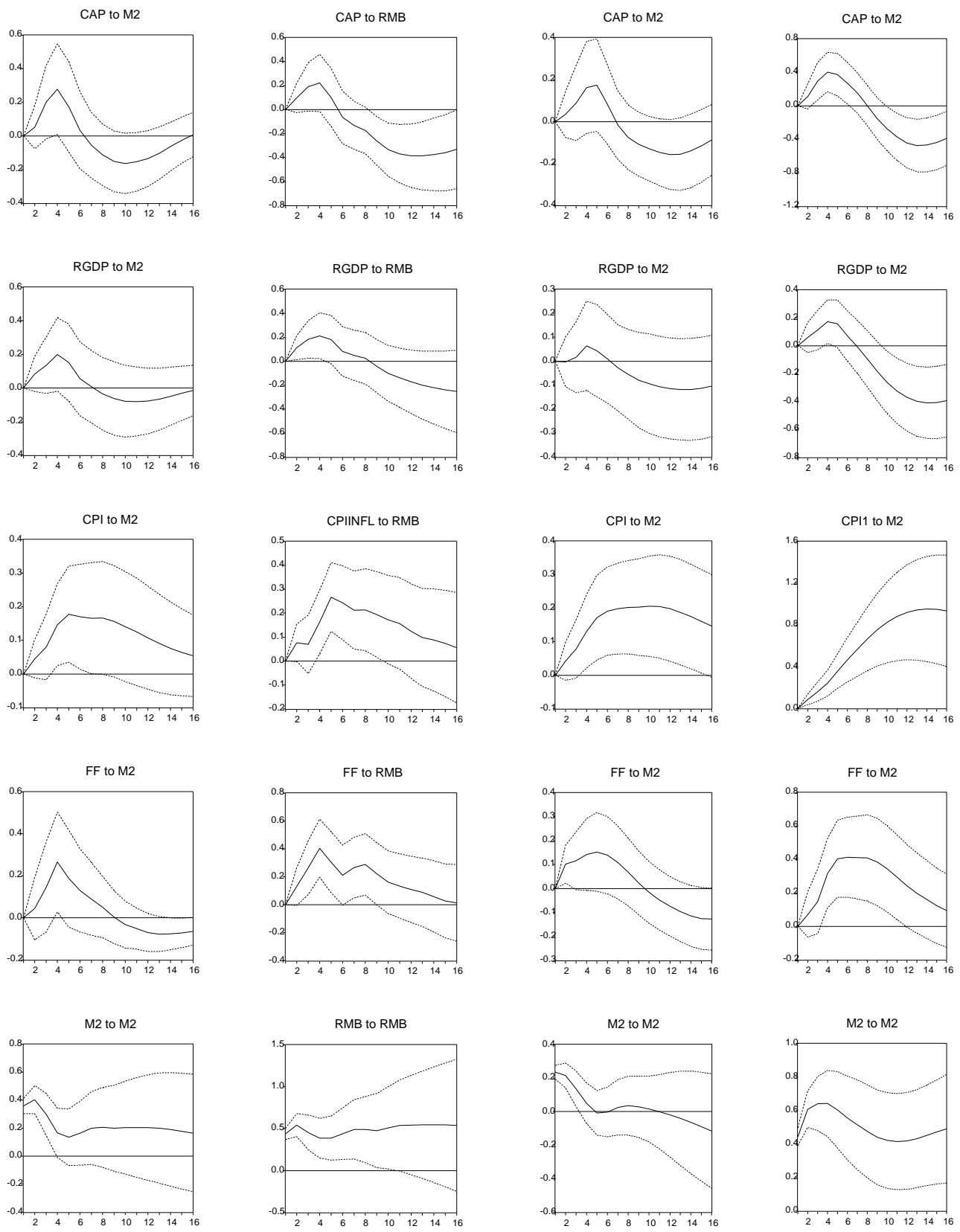

Figure 6.a: Sub-sample stability. Responses to a one-std LM shock in several $\operatorname{VAR}(4)$, with $95 \%$ std error bands (analytical). 
GDP DEFL
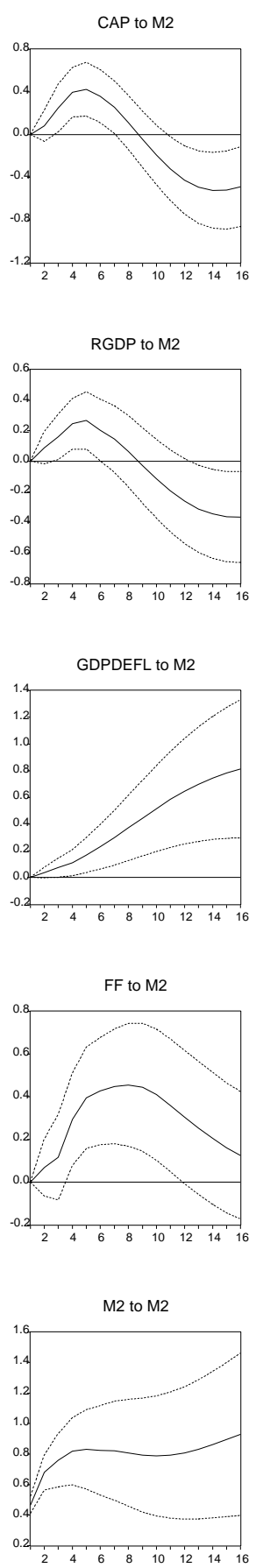

M3
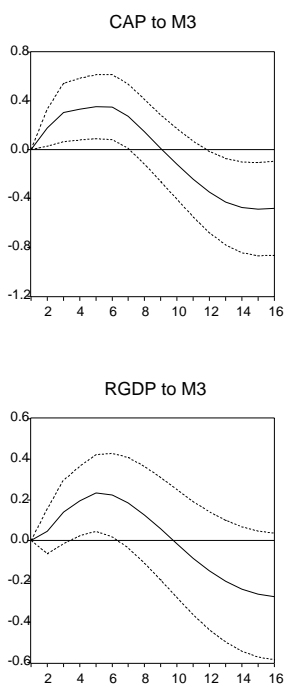

$\mathrm{CPI}$ to $\mathrm{M} 3$
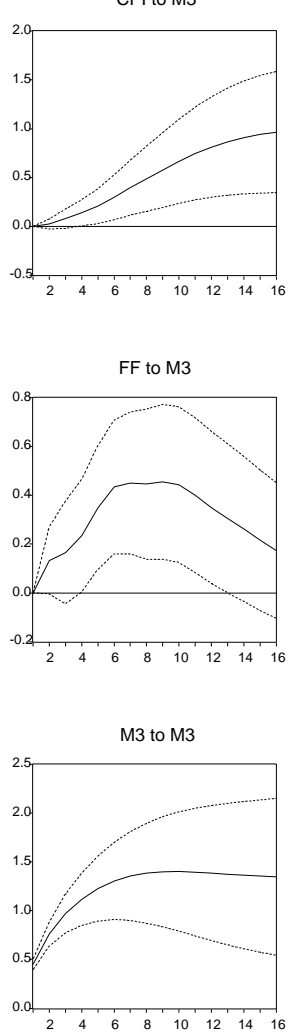

M0

M1
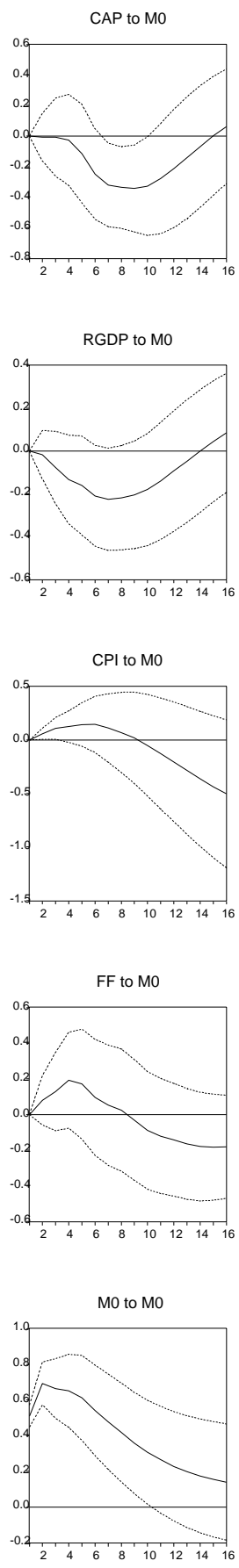
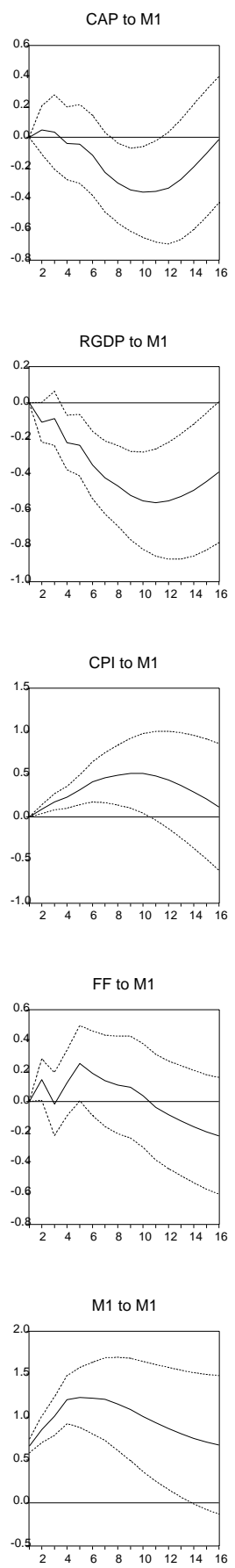

Figure 6.b: Alternative VAR specifications. Responses to a one-std LM shock in several $\operatorname{VAR}(4)$, with $95 \%$ std error bands (analytical). 
10 year yield
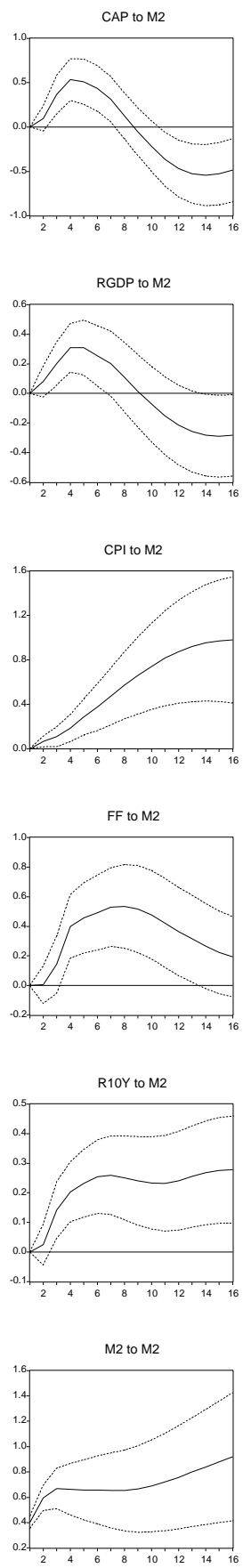

Default Spread
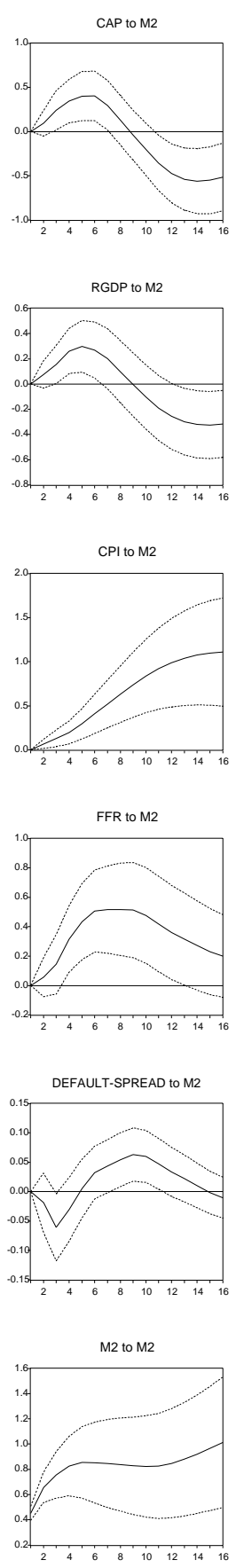

S.\& P. 500
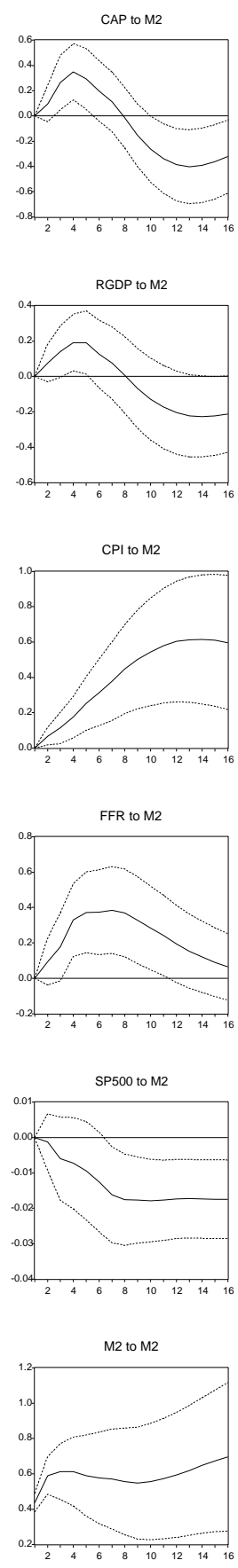

Commodity Price
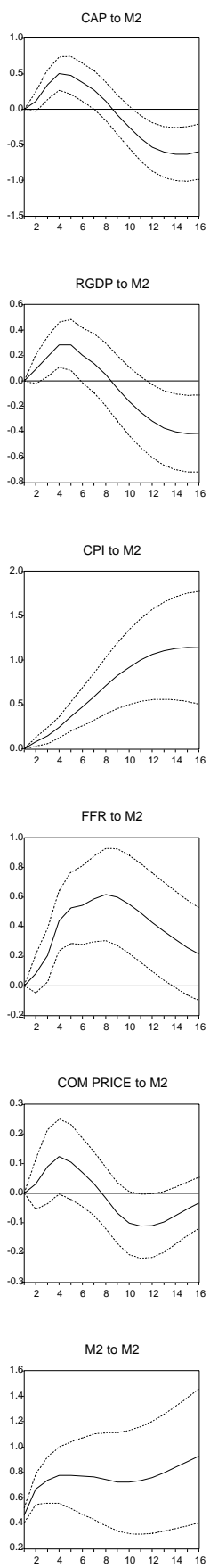

Figure 6.c: Financial variable. Responses to a one-std LM shock in several VAR(4), with 95\% std error bands (analytical). 
Investment
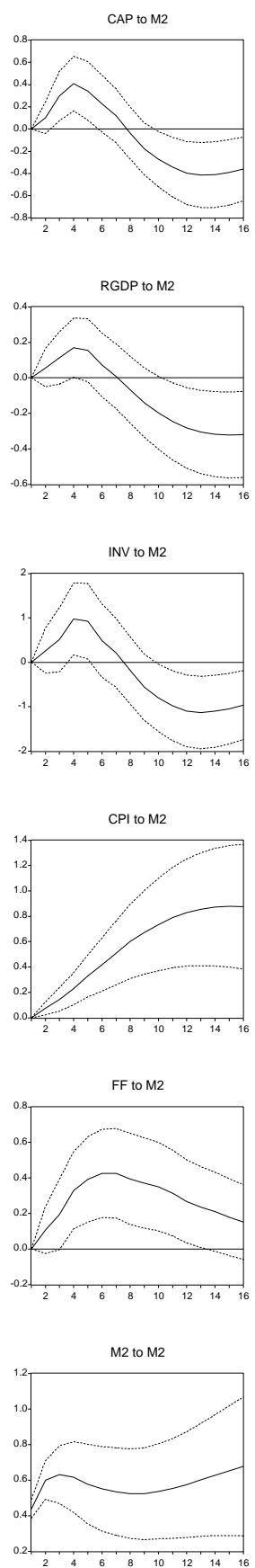

Gov. Cons.
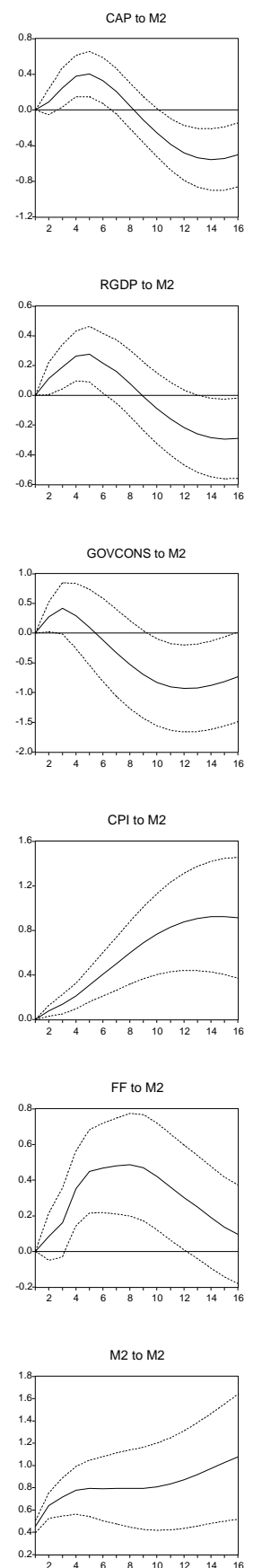

Wages
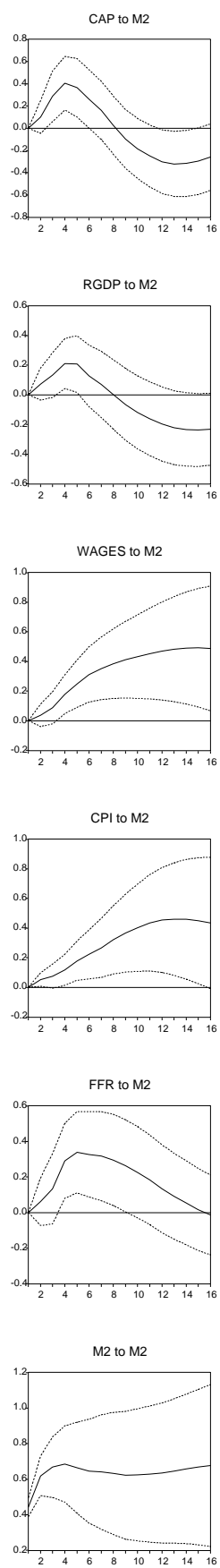

Unemployment
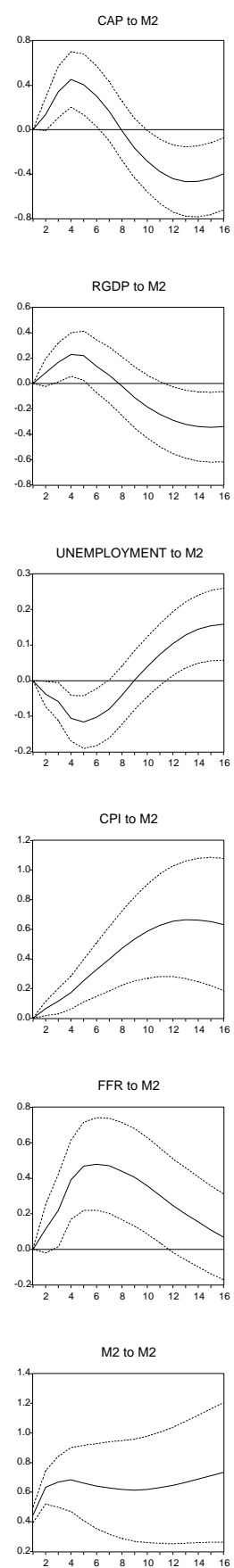

Figure 6.d: Non-financial variables. Responses to a one-std LM shock in several VAR(4), with $95 \%$ std error bands (analytical). 